\title{
How Expectations Shape the Formation of Intrusive Memories: An Experimental Study Using the Trauma Film Paradigm
}

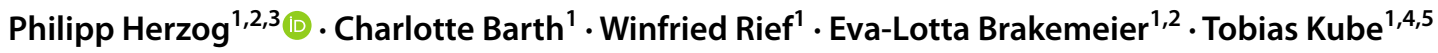

Accepted: 7 January 2022 / Published online: 28 January 2022

(c) The Author(s) 2022

\begin{abstract}
Background Although intrusions are the hallmark symptom of posttraumatic stress disorder, there is still limited knowledge about the processes that contribute to the development of intrusions. Here, we used the well-established trauma film paradigm (TFP) to investigate how expectations about the intensity and controllability of intrusions influence their occurrence. Methods 90 healthy participants underwent the TFP before they were randomized to one of three conditions manipulating their expectations about intrusions: positive expectations group; negative expectations group; control group. The primary outcome was the frequency and severity of intrusive memories as assessed with an intrusion diary over seven days.

Results The TFP was well implemented, as indicated by significant post-film anxiety and a substantial number of intrusions reported for the subsequent week. The three groups did not differ in their expectations about intrusions and, relatedly, in their experience of intrusions. A mediation analysis revealed that the influence of post-film anxiety on intrusive memories was fully mediated by expectations.

Conclusions Despite the failure of the expectation manipulation, the results of the mediation analysis support the hypothesis that post-film expectations influence the formation of intrusive memories, suggesting that intrusions may result from maladaptive dynamics between emotional and cognitive processes following trauma(like) experiences.
\end{abstract}

Keywords Trauma film paradigm $\cdot$ Expectations $\cdot$ Intrusions $\cdot$ Intrusive memories $\cdot$ Post-traumatic stress disorder $\cdot$ PTSD

Eva-Lotta Brakemeier and Tobias Kube: Shared senior authorship and contributed equally.

Philipp Herzog

philipp.herzog@staff.uni-marburg.de

1 Division of Clinical Psychology and Psychological Treatment, Department of Psychology, Philipps-University of Marburg, Gutenbergstraße 18, 35032 Marburg, Germany

2 Division of Clinical Psychology and Psychotherapy, Department of Psychology, University of Greifswald, Franz-Mehring-Straße 47, 17489 Greifswald, Germany

3 Department of Psychiatry and Psychotherapy, University of Lübeck, Ratzeburger Allee 160, 23562 Lübeck, Germany

4 Pain and Psychotherapy Research Lab, University of Koblenz-Landau, Ostbahnstr. 10, 76829 Landau, Germany

5 Program in Placebo Studies, Harvard Medical School, Beth Israel Deaconess Medical Center, Brookline Avenue 330, Boston, MA 02115, USA

\section{Introduction}

Although about $70 \%$ of all people experience or witness a traumatic event during their lifetime (Benjet et al., 2016; McLaughlin et al., 2013), a majority seems to recover from it and does not develop a full-blown posttraumatic stress disorder (PTSD). This begs the question of what protective or resilience and risk factors influence the development and maintenance of PTSD-related symptoms (Bonanno et al., 2007, 2011; Marks et al., 2018; Sareen, 2014). Although the understanding of the complex psychopathology of PTSD has become more nuanced in recent years, e.g., by applying current theoretical frameworks from system neuroscience (Kube et al., 2020; Linson \& Friston, 2019; Wilkinson et al., 2017), important empirical questions have not yet been answered sufficiently, such as a deeper understanding of the development and persistence of intrusions.

Network models of PTSD highlight intrusions as a central link between other characteristic symptoms of PTSD and consider them as an 'activator' (Bryant et al., 2017; Haag et al., 2017). Reexperiencing symptoms such as vivid 
intrusive memories are therefore considered as the hallmark symptom of PTSD (Brewin, 2015; Iyadurai et al., 2019; Yehuda et al., 2015) and also a crucial part of other psychological conditions such as anxiety disorder and depression (Brewin et al., 2010). By definition, intrusive memories are involuntary recollections of events experienced as traumatic that appear spontaneously in consciousness (Holmes $\&$ Bourne, 2008). More precisely, around half of all patients reported their intrusive memories as representing sensory experiences, a quarter of them as sensory experiences and feelings, whereas no patients described them as thoughts only (Michael et al., 2005). Further, vividness-often referred to as the "here and now" quality of intrusionsis a core feature of intrusions. That is, intrusive memories are experienced as sensations in the present rather than as a memory of the past, thereby conferring a sense of current threat (Ehlers \& Steil, 1995). Looking more closely at the content of intrusive memories, research has indicated that visual perceptions of events preceding the traumatic event are frequently reported, rather than the most horrifying moment of the actual traumatic event (Ehlers et al., 2002).

For a better understanding of the nature of intrusive memories, i.e., their development and maintenance, research needs not only clinical studies and patients' retrospective reports, but also prospective studies with experimental designs in order to identify causal mechanisms of action (Arnaudova \& Hagenaars, 2017; Ehring et al., 2011). Experimental research into intrusive memories has increased since the beginning of this century, and one of the major achievements was the development of the trauma film paradigm (TFP; for a review of studies that used this paradigm: James et al., 2016) that has been shown to be able to induce intrusive memories in an ethically justifiable manner (Holmes $\&$ Bourne, 2008). Nowadays, the TFP is considered to be an established model to experimentally investigate the psychopathology of PTSD. Within this paradigm, psychological processes that are hypothesized to influence the formation of intrusive memories and reactions to trauma can be manipulated before, during or after the film scenes (James et al., 2016). Recent studies have shown that factors and processes that occur during (i.e., peritraumatic factors) or after trauma exposure (i.e., posttraumatic factors) are considered important (Marks et al., 2018; Ozer et al., 2003), whereas stable personality traits seem to play a subordinate role (Brewin et al., 2000; Laposa \& Alden, 2008; Ozer et al., 2003; Trickey et al., 2012). In the present study, we investigated whether one specific posttraumatic factor, i.e., expectations concerning the intensity and controllability of intrusions, influence the formation of intrusive memories. Before explaining the rationale for that research question in detail, we briefly summarize evidence regarding additional factors that are related to the development of intrusions (for a detailed review of risk and protective factors associated with intrusion development, we refer to Supplemental Material 1).

In line with the emotional processing theory (Foa \& Kozak, 1986; Foa et al., 1989, 1992), experimental data have shown that the higher the state-anxiety immediately after watching the trauma film (post-state anxiety), the stronger the intrusive memories of healthy controls (Hagenaars et al., 2010; Laposa \& Alden, 2008; Laposa \& Rector, 2012; Măirean \& Ceobanu, 2017). Moreover, Laposa and Alden (2008) proposed that the effect of post-state anxiety on intrusive memories could be mediated by cognitive processes. In line with that assumption, research has shown that the emotional reactivity caused by a traumatic event activates important brain structures, which in turn influence cognitive processing in the brain (Cahill \& McGaugh, 1998; Marks et al., 2018; Phelps, 2006). For example, Regambal and Alden (2009) demonstrated that the increase in stateanxiety, as observed when exposed to a traumatic event, indirectly influenced the experience of intrusion memories via cognitive processes and maladaptive coping strategies. In a remarkable review, Marks et al. (2018) proposed a feedback loop model, suggesting that the way the intrusion is appraised influences the distress associated with it, which in turn results in more intrusions over time. In line with that idea, the cognitive model of PTSD (Ehlers \& Clark, 2000) and the cognitive stuck points proposed by Resick and Schnicke (1992) highlight the importance of negative appraisals in the persistence of PTSD and are strongly associated intrusive symptoms. Recently, a review has pointed out that in various studies, an improvement in PTSD symptoms during psychotherapy was associated with a reduction in negative posttraumatic cognitions (Brown et al., 2019). In sum, previous research suggests that dysfunctional cognitive processes related to the (analogue) traumatic event critically influence PTSD symptoms and intrusions in particular.

In recent years, our understanding of dysfunctional cognitions in various mental disorders has been refined: It has been suggested that expectations-defined as future-directed cognitions that refer to the likelihood of the occurrence of specific events or experiences-represent a particularly important subgroup of cognitions (Rief et al., 2015). In depression, for example, dysfunctional expectations have been successfully integrated into the cognitive model of depression (Kube et al., 2018a). In PTSD, dysfunctional expectations also seem to play an important role based on cross-sectional evidence (Herzog et al., 2021), but experimental research addressing potential causal influences is lacking.

In conceptualizing the present study aimed at examining how positive and negative expectations regarding the perception of intrusions influence their occurrence, we considered findings from placebo and nocebo research. In this area of research, it is evident that the expectation to experience 
positive effects after a pharmacological intervention (e.g., taking a pain killer), increases the likelihood of actually experiencing positive effects (e.g., less pain), referred to as the placebo effect; on the other hand, the negative expectations regarding potential side effects of treatments contributes to their occurrence, referred to as nocebo effects (Colloca \& Barsky, 2020). Analogously, it has been assumed in clinical psychological research that expectations regarding the occurrence of symptoms can be changed by positive and negative priming (Bootzin \& Bailey, 2005). This means, for example, that negative expectations about the occurrence of bothersome symptoms can actually lead to the experience of more pronounced symptoms (Bootzin \& Bailey, 2005). In depression research, initial findings suggest that experimentally manipulated expectations influence the development of sadness (Glombiewski et al., 2019) and rumination (Rebstock et al., 2020), both being core symptoms of depression. Drawing on that previous research, the present study sought to investigate whether the induction of positive vs. negative expectations regarding the occurrence of intrusions (e.g., through aggravation after traumatic experiences) influences the experience of intrusions after the TFP.

Some trauma film studies investigated the influence of positive and negative cognitive reappraisal training on the development of intrusions (Woud et al., 2012, 2013, 2018). In particular, a previous study found that nonexplicit, systematic computerized training in reappraisal style following TFP reduced intrusive memories, and symptoms associated with posttraumatic stress over the subsequent week (Woud et al., 2012). In this study, participants were trained to adopt a generally positive or negative appraisal style using a series of scripted vignettes after TFP targeting self-efficacy beliefs and reappraisals of secondary emotions (that is, emotions in response to the emotional reactions elicited by the film). In particular, the training comprised processing a series of reappraisal-related scripted vignettes that appeared to participants as a sentence completion task (i.e., to-be-completed word fragments). Compared with those trained negatively, participants trained positively reported fewer intrusive memories related to the film during the following week, and lower scores on the IES-R (Woud et al., 2012). The results of these studies have indicated that healthy controls in the positively trained group showed a lower frequency and distress of intrusions (for overviews of manipulated cognitive processes in this context: Vasterling \& Arditte Hall, 2018; Woud et al., 2017). Thus, these findings suggest that the "natural" expectations of healthy controls regarding the occurrence of intrusions could be changed by manipulating expectations after the TFP. Building on these findings, the present study aimed to examine how expectations about the intensity and controllability of intrusions influence their occurrence, as induced by the TFP. Specifically, participants watched an aversive film clip footage (trauma film) before being randomized to one of three experimental conditions: the induction of negative expectations regarding intrusions (negative expectations group); the induction of positive expectations regarding intrusions (positive expectations group); control group (CG) receiving no expectation manipulation. Subsequently, participants recorded the occurrence and intensity of intrusions in an intrusion diary during the following week.

We hypothesized that the negative expectation group would experience more intrusive memories over 1 week than the positive expectation group and the CG, while the positive expectation group would report fewer intrusions than the CG group (negative expectations group $>C G>$ positive expectations group). In addition, we hypothesized that, across groups, the effects of post-film state-anxiety on the frequency and distress of intrusions is mediated by expectations. We assumed that higher levels of post-film anxiety are associated with higher levels of negative expectations that are related to more intrusions. In the case of strongly negative post-film experiences, it seems plausible that negative expectations about the consequences of the trauma film emerge, that, in turn, increase the likelihood of actually experiencing intrusions in the following week, much like nocebo effects. These hypotheses are based on the studies summarized above, which suggest that post-traumatic stateanxiety indirectly influence the occurrence of intrusions via cognitive processes (e.g., Laposa \& Alden, 2008; Regambal \& Alden, 2009).

\section{Methods}

This study was a randomized controlled triple-blind study (i.e., participants, instructor, and outcome evaluator were all blind). It was preregistered on Clinical Trials (ClinicalTrials.gov Identifier: NCT03950869) and was approved by the local ethics committee of the Department of Psychology at the Philipps-University Marburg (reference number 2019-07). All participants gave written informed consent and were treated in accordance with the ethical guidelines of the German Psychological Society and the guidelines for human studies of the World Medical Association Declaration of Helsinki.

\section{Participants}

Participants were recruited through the mailing lists of the university for study participation and with leaflets spread out in the city. Inclusion criteria were: at least 18 years old; fluent in German. As with other studies using the TFP, the exclusion criteria were quite strict in order to ensure that no participant with mental vulnerabilities or disorders would undergo the distressing film clips. The exclusion criteria 
were checked as follows: first, in an online prescreening, people with substantial working experiences in the medical field (e.g., nurses, paramedics, etc.), people with significant visual impairment and a medical history of heart disease or epilepsy, people with a history of and proneness to fainting and people consuming excessively violent imagery material, and students of psychology and medicine ${ }^{1}$ were excluded. In a second step, people with a history of traumatic experiences (i.e., having experienced any traumatic event in the past) as assessed by the Life-Event-Checklist for DSM-5 (LEC-5; Krüger-Gottschalk et al., 2017; Weathers et al., 2013) and people at risk for depression as reflected by a sum score of at least ten in the Patient-Health Questionnaire-9 (PHQ-9; Kroenke et al., 2001; Manea et al., 2012), accompanied by additional clinical evaluation in a telephone interview, were also excluded. In a third step, a pre-study interview consisting of the Structured Clinical Interview for DSM-IV (SCIDI; First et al., 1997) and the Columbia-Suicide Severity Rating Scale (C-SSRS; Posner et al., 2011) was conducted to exclude people with a current mental disorder and current suicidal thoughts/behavior or non-suicidal self-injury behavior. If any mental disorder and/or risk for suicide was identified, participants were offered the possibility of receiving more information on their condition and potential treatment options. To ensure a proper application of the observerevaluated measures, all interviewers received a $4 \mathrm{~h}$ training in SCID-I and C-SSRS including theoretical and practical elements by the first author. Additionally, each of the three interviewers passed successfully an online-based training (RFMH-C-SSRS Transnational Training and Assessment Campus (Posner et al., 2011)).

The sample size was determined via an a-priori power analysis using G*Power Version 3.1 (Erdfelder et al., 2009; Faul et al., 2007). The power analysis indicated a minimal sample size of $\mathrm{N}=84$ participants to uncover medium to large effects in the primary outcome, i.e., group differences in the frequency of intrusive memories, in a one-way ANOVA ( $\mathrm{f}=0.35$; test power of $1-\beta=.80 ; \alpha=.05$ ). Further analysis indicated that in order to perform the manipulation check regarding the TFP using a t-test for dependent samples (one-sided test), $\mathrm{N}=45$ participants would be needed to obtain a medium effect $(\mathrm{d}=0.50)$ at a significance level of $\alpha=.05$ and a test power of $1-\beta=.95$.

In total, an appointment for study participation could be made and confirmed for $n=101$ subjects, of whom $n=9$ subjects either did not show up for the appointment or cancelled (no replacement appointment). Only $\mathrm{n}=2$ subjects were excluded from the study during the study implementation

\footnotetext{
1 These participants were excluded as we worried that students of psychology and medicine might be too familiar with studies using expectation manipulations.
}

because $\mathrm{n}=1$ person did not meet the criteria of the second pre-screening (clinical abnormalities in SCID-I) and $\mathrm{n}=1$ person had to stop watching the trauma film due to too strong emotional stress. This resulted in a total sample of $\mathrm{N}=90$ participants included in the study. Participants who completed the study received financial compensation of $40 €$. If participants did not complete the study, they were paid proportionally, i.e., $10 € / \mathrm{h}$ of time spent in the study. The participant flow chart is displayed in Fig. 1.

\section{Procedure}

Participants were informed that the aim of this study was to investigate how violent film contents are remembered. Our study procedure was very similar to previous studies using the TFP (see for example: James et al., 2015): On Day 1, participants entered the laboratory and completed several pre-film measures (as mentioned below), watched the intrusion-inducing trauma film and completed the post-film measures. Before watching the film, they were instructed to watch the film as if they were a witness present at the scenes or a by-stander. Participants were asked not to close their eyes or distract themselves. During the film, the lights were turned off and noise-canceling headphones were used. Afterwards, participants were asked to follow the instructions in the computerized questionnaire, in complete absence of the investigator to eliminate a potential Rosenthal-effect (e.g., by soothing the participant). After watching the film, all participants were randomly assigned to one of three conditions through the randomization procedure of the survey software using an urn model with layback. The experimenter was not aware of that randomization. After the manipulation, participants' expectations were assessed and the daily intrusion diary for 1 week was explained and handed out. After seven days, participants came back to the laboratory, completed follow-up measures, handed over their intrusion diary, and were debriefed. The full study design is displayed in Fig. 2.

When planning the study, we extensively discussed the temporal ordering of the experimental design as it would have been also plausible to manipulate expectations before watching the trauma film. Ultimately, we weighted different manipulation aspects related to our study aim (e.g., peritraumatic processing through priming effects vs. posttraumatic processing through appraisal effects, perception of the trauma film and trauma memory encoding, imagination of the potential consequences of the trauma film before watching, strength of the manipulation) against each other, and decided to use the expectation manipulation after watching the trauma film. 
Fig. 1 Participant flow chart

Initially interested persons

(number of sent links for online-based pre-screening)

$$
(n=215)
$$

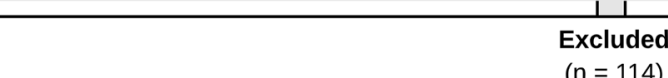

Missing data ( $1^{\text {st }}$ pre-screening) $(n=40)$

Not meeting inclusion criteria ( $1^{\text {st }}$ pre-screening)/inaccessible by phone $(n=74)$

Appointment confirmations

$(n=101)$

1

Excluded

$(n=9)$

did not show up/cancelled appointment

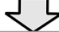

$1^{\text {st }}$ Laboratory appointment

$(n=92)$

\section{1}

Excluded

$(n=2)$

Not meeting inclusion criteria ( $2^{\text {nd }}$ pre-screening; SCID-I)

Discontinued participation due to emotional distress caused by traumafilm
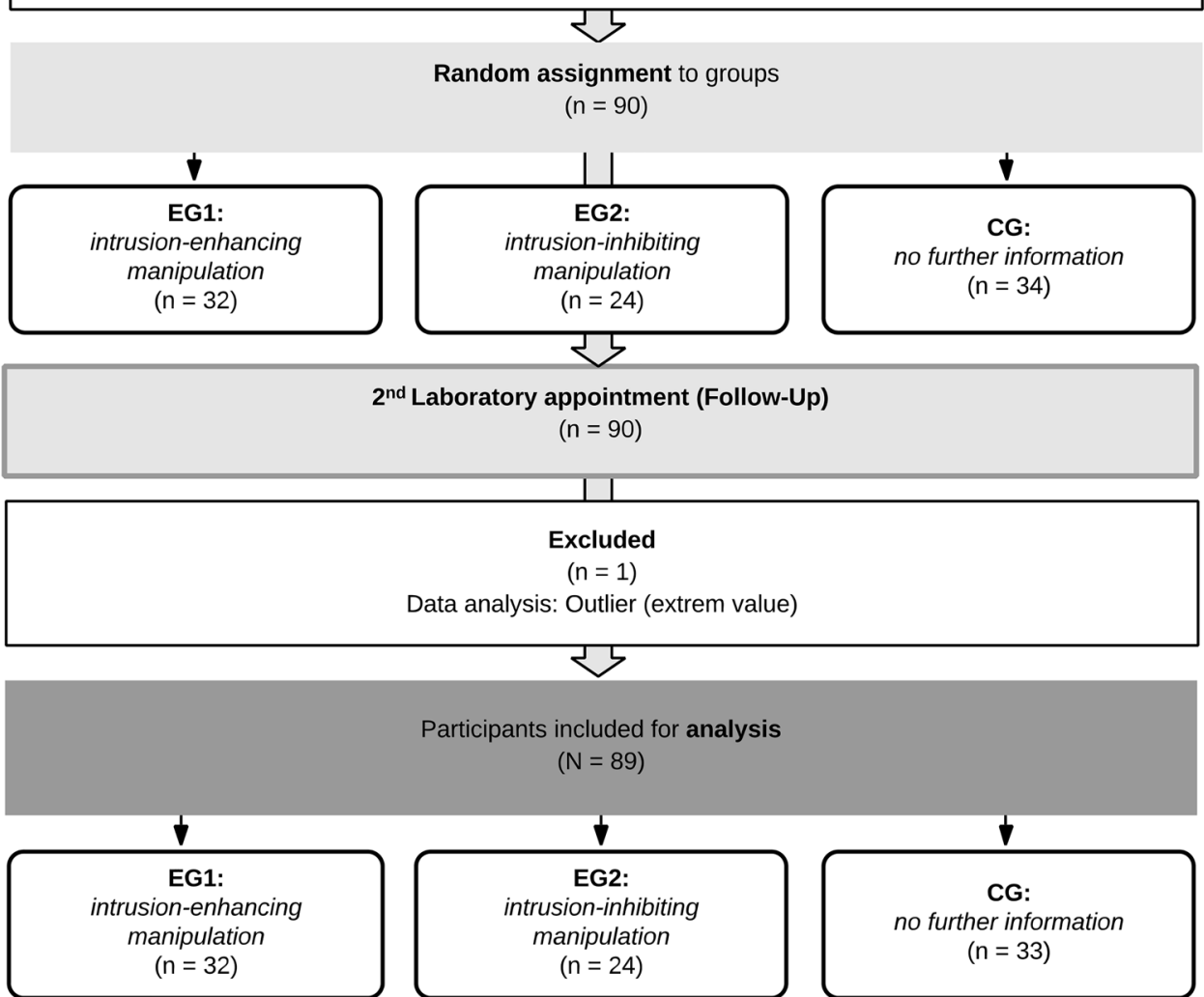

\section{Trauma Film}

The trauma film used in this study consisted of four short film clips and lasted 12:39 min. Two of them were excerpts from the film "Irreversible" (Noé, 2002), one of which showed a physical violence scene (2:37 $\mathrm{min})$, and the other one showed a scene of sexualized violence of a man against a woman (4:04 min). The third film clip showed a car accident as a consequence of texting while driving (2:34 min) (P. Watkins-Hughes (U.K., 2009)). The fourth clip showed 
Fig. 2 Study design and basic procedure of the experimental paradigm to investigate expectations in the development of intrusive memories

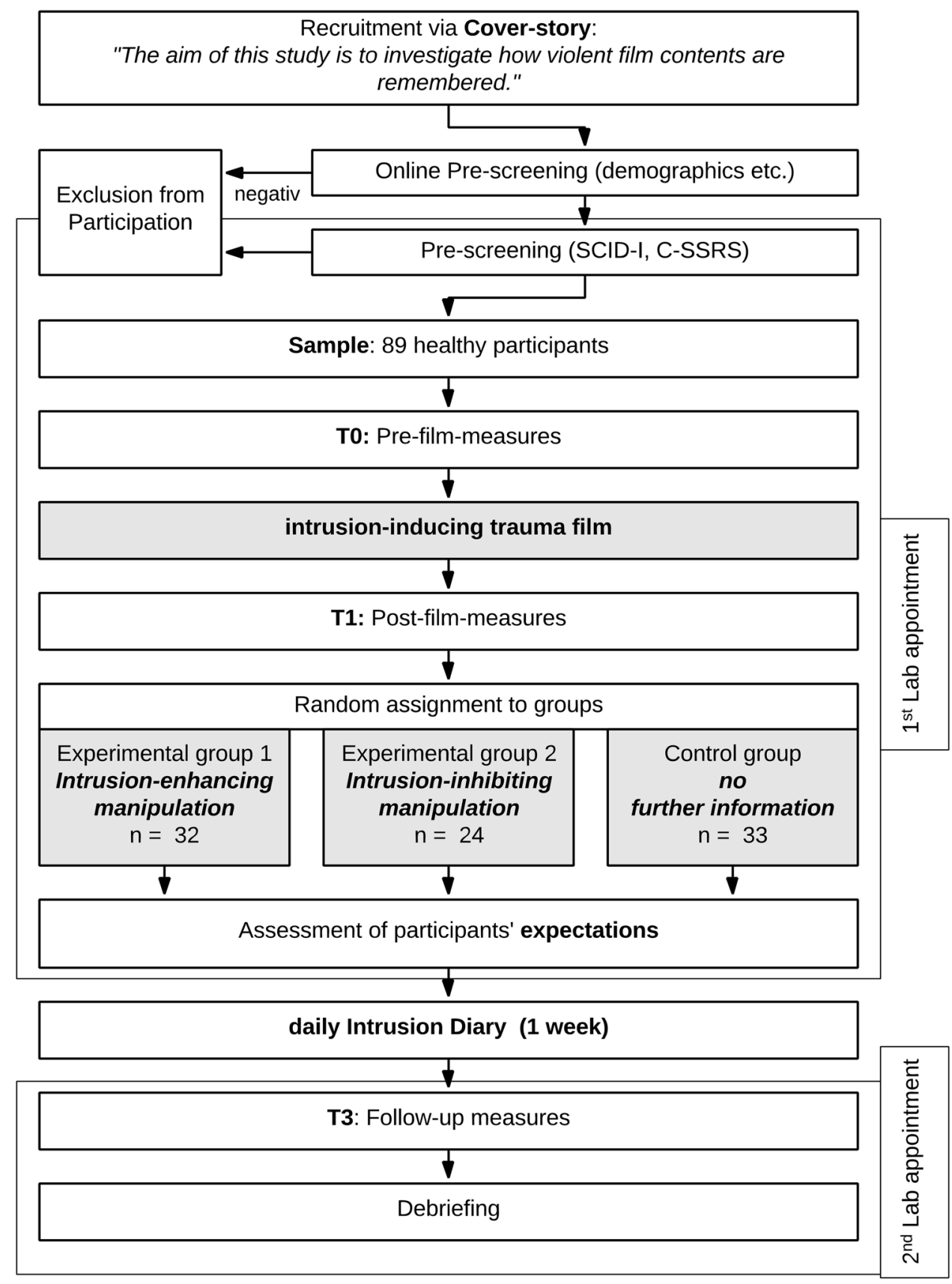

sexualized violence of a woman against a man taken from the movie "Antichrist" (3:00 min) (von Trier, 2009). In order to trigger intrusive memories as reliably as possible, specific film clips were chosen that differed in the type of violence or their content. The first three film clips were recommended to be used in the TFP by Arnaudova and Hagenaars (2017): In this study, the authors found that those film clips evoked strong negative emotions, such as disgust, distress and embarrassment, and that the graphic violent scenes asked for a higher level of involvement, which is considered as an important factor in the TFP. The last film clip was used in a previous trauma film study by Rattel et al. (2019) and was added as a counterpart to the scene of sexualized violence by men toward women in Irreversible (Noé, 2002). In line, the results of this study corresponded to previous TFP studies by showing significant outcomes for the experience of distress and disgust.

\section{Experimental Conditions and Instructions}

In our experimental study, we compared three conditions: Participants from the positive expectation group and the negative expectation group watched a film clip of a 'trauma expert' (i.e., one of the authors: ELB). In each of the two 
videos, the trauma expert provided information on the trauma film and the development of intrusive memories, with the aim of inducing different expectations regarding the intensity and controllability of intrusions (see Supplemental Material 2). In the negative expectation group, the trauma expert specifically raised the expectation that it was very likely for them to reexperience the highly stressful film clips they watched in the form of intrusive memories. In addition, it was emphasized that they could not consciously influence these intrusions. Subsequently, the trauma expert stressed the psychological and neurobiological aspects of the development of intrusions on a supposedly scientific level by means of conveying stronger credibility. In the positive expectation group, participants were informed that the potentially traumatic content of the film clip would most likely not trigger any intrusions or other forms of reexperiencing. Their sufficient resources would help them in processing what they had seen without suffering any consequences. Additionally, the trauma expert made reference to the previously conducted elaborate examination (i.e., prescreening) that guaranteed the sufficient level of the participants' mental health.

In other words, in the EG1 film clip, expectations on the severity and frequency of intrusions are increased while expectations on the controllability of intrusions are decreased. In the EG2 film clip, expectations on the severity and frequency of intrusions are decreased while expectations on the controllability of intrusions are increased. As both 5-min-long film clips of the two experimental groups were meant to debrief the consequences of the trauma film by an acknowledged expert in this field, we hypothesized that the intrusion-promoting manipulation (EG1) would show a higher frequency of intrusive memories of a trauma film than the intrusion-inhibiting manipulation (EG2). Both film clips were about the same length. A control group (CG) received no further information and waited instead the same amount of time the other groups were receiving the manipulation (i.e., watching the film clip).

\section{Measures}

\section{Primary Outcome}

Frequency and severity of intrusive memories. The primary outcome measure of our study was defined as the frequency and severity of intrusive memories, as assessed with the daily intrusion diary by James et al. (2015) (which was translated into German for the purpose of the present study).

Participants were asked to complete this pen-and-paper diary for 7 days after the first laboratory assessment (where they saw the trauma film). Participants were instructed to note any intrusive memories in relation to the trauma film. They were asked to note the frequency of all intrusions per day, with each day being divided into morning, afternoon, and evening, and they were asked to mark when they experienced an intrusion. For each intrusion, they indicated the quality of the intrusion (image, thought or both), the intensity of the intrusion, and the distress caused by the intrusion, with both intensity and distress being rated on a scale ranging from 0 ("not at all") to 10 ("extremely"). In addition, participants were asked to note the content of the intrusion and the situation in which the intrusion occurred.

An intrusion noted in the diary was pre-specified and considered as a "valid" intrusion if it had not been (1) indicated with distress $(<1)$, (2) popped out as a result of active thinking or rumination or through active communication, or (3) described as nonspecific thoughts and/ or images. Intrusions with no distress were considered as "invalid" for two reasons: First, intrusions-as defined by the DSM-5 (American Psychiatric Association, 2013)are recurrent, involuntary, and distressing memories of the traumatic event. The lowest threshold to operationalize this definition was given by a distress score $<1$. Second, and in line with this definition, this criterion was also chosen to differentiate intrusions from recurring thoughts (e.g., thoughts associated with worry and rumination) in general. The first criterion was checked using the noted distress score (0 to 10) in the diary. To check the second criterion, the situation was analyzed for each intrusion that occurred and a decision was made as to whether the occurrence was due to a conscious engagement with the study (e.g., thinking, ruminating, talking about it), while the diary per se as a reminder/trigger was allowed. To examine the third criterion, it was checked whether a reference to at least one of the film clips could be reasonably drawn. If this was not the case, the intrusion was rated as "non-specific" and excluded from further analysis.

To analyze the valid intrusions as assessed with the intrusion diary, intrusive memory frequency across 7 days was summed up, with higher sum scores reflecting a higher frequency of intrusions. The severity of intrusions was determined by combining the average score of the intensity and distress scale across all intrusions, with higher values indicating a higher severity of intrusions.

For the frequency of intrusions, statistical analyses revealed a mean of $M=4.93(S D=3.87)$ intrusions experienced over the course of the week, which is comparable to mean values of other TFP studies (e.g., $M=5.5$ as reported by James et al. (2015) and $M=4.64$ as reported by Holmes et al. (2004)). The range within the study was from Min $=0$ to Max $=19$ experienced intrusions, while $88.8 \%$ of all participants experienced at least one intrusion. 


\section{Secondary Outcomes}

Distress caused by the trauma film. The secondary outcome measure was the distress caused by the trauma film, assessed by an adapted version of the Impact of Event Scale-Revised (IES-R; Maercker \& Schützwohl, 1998). At the follow-up measurement, i.e., 7 days after the experimental manipulation, participants were asked to rate 22 items assessing distress related to contents of the trauma film (e.g., "Pictures about the film popped into my mind."). For this purpose, participants indicated how often each reaction occurred over the past seven days. Items are rated on a 4-point-Likert-scale ranging from 0 ("not at all"), 1 ("rare"), 3 ("sometimes") to 5 ("often"). The IES-R consists of three subscales: "intrusion", "hyperarousal", and "avoidance". The total score ranges from 0 to 110 , with higher values reflecting higher distress. In addition, the sum score for the intrusion subscale is calculated separately, with total scores ranging from 0 to 35 (Items 1, 3, 6, 9, 14, 16, 20). In our sample, a reliability analysis yielded a Cronbach's $\alpha_{\text {total }}=.87$ of the total scale and a Cronbach's $\alpha_{\text {intrusion }}=.79$ of the intrusion subscale. In our sample, the mean score was $M=13.22(S D=3.23)$, ranging from $\min =7$ to $\max =23$.

Laboratory assessment of intrusive memories. As the aforementioned measures relied on retrospective estimates by participants, intrusive memories were additionally assessed in the laboratory in the Intrusion Provocation Task (IPT; Çili \& Stopa, 2015). In addition to diary intrusion assessment, laboratory intrusion assessment by recording intrusive memories after exposure to trigger cues using the IPT is a simple and feasible way to assess intrusions throughout the peri-intrusion window (Lau-Zhu et al., 2018). In the IPT, participants were presented with a ten-second long neutral still image from each of the film clips. Afterwards, they were instructed to think non-purposefully for the next two minutes and report the occurrence of any intrusions by raising a finger. The investigator counts how often the participant lifts the finger. The IPT intrusion score is calculated by the total frequency of intrusions, with higher values reflecting more intrusions. Participants completed the IPT at the follow-up measurement as in other studies (e.g., Lang et al., 2009; Malik et al., 2014).

\section{Sociodemographics and Other Measures}

Sociodemographic questions. Participants were asked about their age, gender, highest educational degree and current employment status.

Anxiety measure The State-Trait-Anxiety-Inventory (STAI; Spielberger et al., 1970) is a questionnaire assessing two dimensions of anxiety; namely, anxiety as a trait (STAIT), and anxiety as a state, i.e., a transient emotional state (STAI-S). The STAI-S comprises 20 anxiety-related items which are rated by participants on a 4-point Likert-scale ranging from $1=$ "not at all" to $4=$ "totally". Total scores range from 20 to 80 , with higher scores indicating higher state anxiety level. The cut-off for a clinically significant anxiety state is between 39 and 40 . The STAI-S was used in this study for the manipulation check in the German Version (Laux et al., 1981). A reliability analysis in our sample indicated a Cronbach's $\alpha=.92$ at T0 (pre-state anxiety) and a Cronbach's $\alpha=.93$ at T1 (post-state anxiety). Convergent validity was assured by a significant correlation between the STAI-S and the subscale Fear of the PANAS-X prior (T0: $\mathrm{r}=.51, \mathrm{p}<.001)$ and after watching the trauma film (T1: $\mathrm{r}=.76, \mathrm{p}<.001)$, which can be considered high according to Cohen (1988).

Expectation Questionnaire. Expectations about the intensity and controllability of intrusions were assessed with the expectations about intrusive memories scale (EIMS), which was developed for the purpose of the present study as no scale to measure this specific concept was available at the time of study planning. This scale was developed to assess participants' assessment of the anticipated intensity of possibly occurring intrusions (e.g., "Whenever I experience intrusive memories over the next week, it will cause me severe distress.") and their ability to control them (e.g., "Whenever I experience intrusive memories over the next week, I will be able to cope with them well."), each with 6 items. After inverting negatively formulated items, all item scores are summed up to compute a total score, with higher values indicating more positive/functional expectations. A reliability analysis in our sample revealed a Cronbach's $\alpha=.81$. After inspecting the item-scale-statistics, item 6 and item 9 were removed from the scale (Corrected item-total correlation $\mathrm{r}<.3$ ). The reliability of the resulting 10 -item EIMS increased to Cronbach's $\alpha=.85$. To detect the latent factor structure, a principal component analysis was computed. While the Kaiser-criterion supports a 2-factor solution, the Scree-plot, a parallel analysis according to Horn (1965) and the MAP-test plead for a single-factor-solution "expectations". This factor accounts for $46.4 \%$ of the total variance. In addition, content validity aspects legitimize a single-factor solution. Therefore, all statistical analysis will be conducted with this single-factor-solution. Correlations between expectations and outcome measures were conducted (one-tailed): expectations were significantly correlated with total score of the IES-R $(r=-.40, p<.001)$ and the IES-R intrusion subscale $(r=-.35, p<.001)$, and non-significantly with the frequency of all intrusions $(r=-.04, p=.37)$, frequency of valid intrusions $(r=-.17, p=.06)$ and intrusion provocation task $(r=-.13, p=.12)$.

Diary Compliance Rating. Participants rated on a scale from 0 to 10 how accurate they were in reporting intrusions in the intrusion diary. The results indicate that participants filled out the diary conscientiously and reported almost all intrusions accurately $(M=8.2 ; S D=1.4)$. These findings are in line 
with diary compliance ratings of another study which reported almost identical values ( $M=8.15$; James et al., 2015).

Follow-up Interview. The majority of our sample did not question the study and no participants uncovered the real objective of the study (i.e., examining the effects of expectations on intrusive memories). Detailed information on the results of the follow-up interview can be found in the Supplemental Material (see Supplemental Material 3).

\section{Statistical Analyses}

For the graphics and the analysis of diary data, we used Microsoft Excel. The online software Lucidchart was used for the creation of flow charts and path models. All statistical analyses were conducted in IBM SPSS $®$ Statistics (Version 21) and the PROCESS Makro Version 3.4 (Hayes, 2018).

Preprocessing. According to Tabachnick and Fidell (2013), all scales included in the statistical analyses were inspected for outliers and extreme values using descriptive analyses and box-whisker plots. After descriptive examination of the data, it was confirmed that outlier values of the individual data were neither implausible nor measurement errors, which is why the corresponding participants did not have to be excluded from further analyses. However, only one participant with an extreme value on the scale "intrusion frequency" was not included in further statistical analyses, because its value of reported intrusions $(n=45)$ was more than three times of the interquartile range above the third quartile resulting in a justifiable unsoundness of the plausibility and credibility of this value (Tabachnick \& Fidell, 2013). Regarding the qualitative aspect of excluding this participant, the content of the reported intrusions was examined revealing that the participant appeared to not have fully grasped the concept of intrusions from the beginning. As a result, the final data set included $\mathrm{N}=89$ participants (see also the participant flow chart in Fig. 1).

Induction of anxiety by trauma film paradigm. The effects of the TFP on anxiety were performed with a t-test for dependent samples incorporating pre-and post-state anxiety measures and, respectively, the effect size. For further investigation, a single factor ANOVA was used to check whether the three experimental groups differed significantly in poststate anxiety.

Manipulation check. We tested through a one-way ANOVA whether the three experimental groups differed in their expectations about intrusive memories, as assessed with the EIMS. If the manipulation was successful, there would most positive expectations in the positive expectations group and least positive expectations in the negative expectations group.

Group differences on primary and secondary outcomes. An one-way ANOVA was performed to determine differences between the experimental groups in the primary outcome, i.e., the frequency and severity of intrusions (both with and without pre-specified criteria). Possible group differences in the secondary outcomes, i.e., the distress caused by the trauma film and participants' responses to the intrusion provocation task were also examined using ANOVA.

Mediation analyses. For the mediation analyses, a slightly different operationalization of the primary outcome was used, as proposed in previous work (Laposa \& Alden, 2008; Laposa \& Rector, 2012). In particular, the dependent variable composed a multimethod combination of the frequency of intrusions as noted in the diary (intrusion frequency) and the "intrusion" subscale of the IES-R (intrusion distress). In the next step, the sum scores of both measures were transformed into standardized variables $(M=0, S D=1)$, allowing us to combine the $\mathrm{z}$-scores into one combined intrusion score. Higher values of this indicator of the overall intrusion experience reflect a more pronounced experience of intrusions. By generating a combination measure, it was possible to reduce the number of individual analyses performed, thus reducing the risk for the type I error for the following statistical calculations (Eid et al., 2017). For the mediation analyses, multiple linear regression models were computed. In the assumed path models, the independent variable (X) is post-state anxiety, which is represented by the sum score of the STAI-S at measurement time $\mathrm{T} 1$. The intrusion experience represents the dependent variable (Y). The total scores of the expectations scale (EIMS) were entered as the mediator variable (M).

\section{Results}

\section{Sample Characteristics}

In our sample, the mean age was $M=24.0(S D=3.5)$ and $47.8 \%$ were female. With regard to the highest education attainment, more than half of the participants obtained a degree comparable to the General Certificate of Education Advanced Level (GCE A-Levels, 56.7\%), while about one third had a university degree (33.3\%). Almost all of the participants were still enrolled in their studies (97.8\%) indicating a typical German student sample. The sociodemographic characteristics of the sample, separated by experimental condition, are displayed in Table 1. Of note, the distribution of participants across groups was not equal due to the randomization procedure, which used an urn model with layback.

\section{Implementation of the Trauma Film Paradigm (TFP)}

To examine the validity of the TFP as implemented in the present study, the difference of the state-anxiety measures was computed. Descriptive statistics showed a mean value of $M=32.30(S D=8.63)$ for pre-state anxiety (before watching the trauma film). For post-state anxiety (after watching 
Table 1 Sociodemographic characteristics of the total sample and each experimental condition
Table 2 Descriptive statistics of the total sample and each experimental condition

\begin{tabular}{|c|c|c|c|c|}
\hline Variable & $\begin{array}{l}\text { Negative expec- } \\
\text { tations group } \\
n=32\end{array}$ & $\begin{array}{l}\text { Positive expec- } \\
\text { tations group } \\
n=24\end{array}$ & $\begin{array}{l}\text { Control group } \\
n=34\end{array}$ & $\begin{array}{l}\text { Total } \\
n=90\end{array}$ \\
\hline Age, $M(S D)$ & $23.5(2.9)$ & $24.1(2.5)$ & $24.4(4.5)$ & $24.0(3.5)$ \\
\hline \multicolumn{5}{|l|}{$\operatorname{Sex}, N(\%)$} \\
\hline Female & $15(46.9 \%)$ & $11(45.8 \%)$ & $17(50.0 \%)$ & $43(47.8 \%)$ \\
\hline Male & $17(53.1 \%)$ & $13(54.2 \%)$ & $17(50.0 \%)$ & $47(52.2 \%)$ \\
\hline \multicolumn{5}{|c|}{ Highest educational attainment, $N(\%)$} \\
\hline Advanced technical certificate & $2(6.3 \%)$ & $4(16.7 \%)$ & $2(5.9 \%)$ & $8(8.9 \%)$ \\
\hline GCE A-levels & $22(68.8 \%)$ & $12(50.0 \%)$ & $17(50.0 \%)$ & $51(56.7 \%)$ \\
\hline University degree & $7(21.9 \%)$ & $8(33.3 \%)$ & $15(44.1 \%)$ & $30(33.3 \%)$ \\
\hline Another degree & $1(3.1 \%)$ & - & - & $1(1.1 \%)$ \\
\hline \multicolumn{5}{|l|}{ Current occupation, $N(\%)$} \\
\hline Student & $32(100 \%)$ & $24(100 \%)$ & $32(94.1 \%)$ & $88(97.8 \%)$ \\
\hline Employed & - & - & $2(5.9 \%)$ & $2(2.2 \%)$ \\
\hline Unemployed & - & - & - & - \\
\hline Other & - & - & - & - \\
\hline
\end{tabular}

Note. $M=$ mean, $S D=$ standard deviation, $N=$ number

\begin{tabular}{lllc}
\hline Variable, $M(S D)$ & $\begin{array}{l}\text { Negative expecta- } \\
\text { tions group } \\
n=32\end{array}$ & $\begin{array}{l}\text { Positive expecta- } \\
\text { tions group } \\
n=24\end{array}$ & $\begin{array}{l}\text { Control group } \\
n=34\end{array}$ \\
\hline $\begin{array}{l}\text { Expectations (EIMS) } \\
\text { Primary outcome }\end{array}$ & $41.63(5.90)$ & $43.25(3.90)$ & $42.36(5.34)$ \\
$\begin{array}{l}\text { Frequency of intrusive memories (Diary) } \\
\text { Secondary outcome }\end{array}$ & $5.00(3.84)$ & $3.63(3.31)$ & $5.82(4.10)$ \\
$\begin{array}{l}\text { Distress (IES-R) } \\
\begin{array}{l}\text { Distress (IES-R subscale intrusions) } \\
\text { Intrusion provocation task (IPT) }\end{array}\end{array}$ & $\begin{array}{l}12.94(2.83) \\
4.25(3.16)\end{array}$ & $\begin{array}{l}13.13(3.37) \\
3.75(3.22)\end{array}$ & $\begin{array}{l}13.58(3.54) \\
4.41(2.71)\end{array}$ \\
\hline
\end{tabular}

Note. $M=$ mean, $S D=$ standard deviation, $n=$ number the trauma film), a mean value of $M=52.01(S D=11.62)$ was recorded. A t-test for dependent samples showed that the state anxiety increased significantly from $\mathrm{T} 0$ to $\mathrm{T} 1$, $\mathrm{T}(88)=17.46, \mathrm{p}<.001, \mathrm{~d}_{\mathrm{z}}=1.84$, reflecting a large effect according to Cohen (1988). The results of an one-way ANOVA showed that there were no statistically significant differences between the groups in post-state anxiety, F (2, $86)=0.89, p=.42$. The descriptive statistics of the expectation questionnaire and the primary and secondary outcomes of the total sample and separated by experimental condition are depicted in Table 2.

\section{Manipulation Check}

An one-way ANOVA indicated no significant group differences in the expectations for intrusive memories scale, $F(2,86)=0.67, p=.52, \eta_{p}^{2}=.02$. Thus, the manipulation was not successful in differentially altering participants' expectations.

\section{Results for the Primary Outcome: Group Differences in Intrusive Memories}

The one-way ANOVA indicated significant differences between the experimental groups in the frequency of all intrusions, $F(2,86)=3.16, p<.05, \eta_{p}^{2}=.07$. Post hoc comparisons indicated that the positive expectancy group significantly differed in the expected direction from both the negative expectancy group, $t(54)=2.29, p<.05, d=0.60$, and the control group, $t(55)=2.56, p<.01, d=0.71$, reflecting medium to large effects. In other words, the positive expectancy group reported significantly less intrusions than the negative expectancy and control group. The negative expectancy group and the control group did not differ from each other, $t(63)=-0.18, p=.86, d=0.04$. However, when 


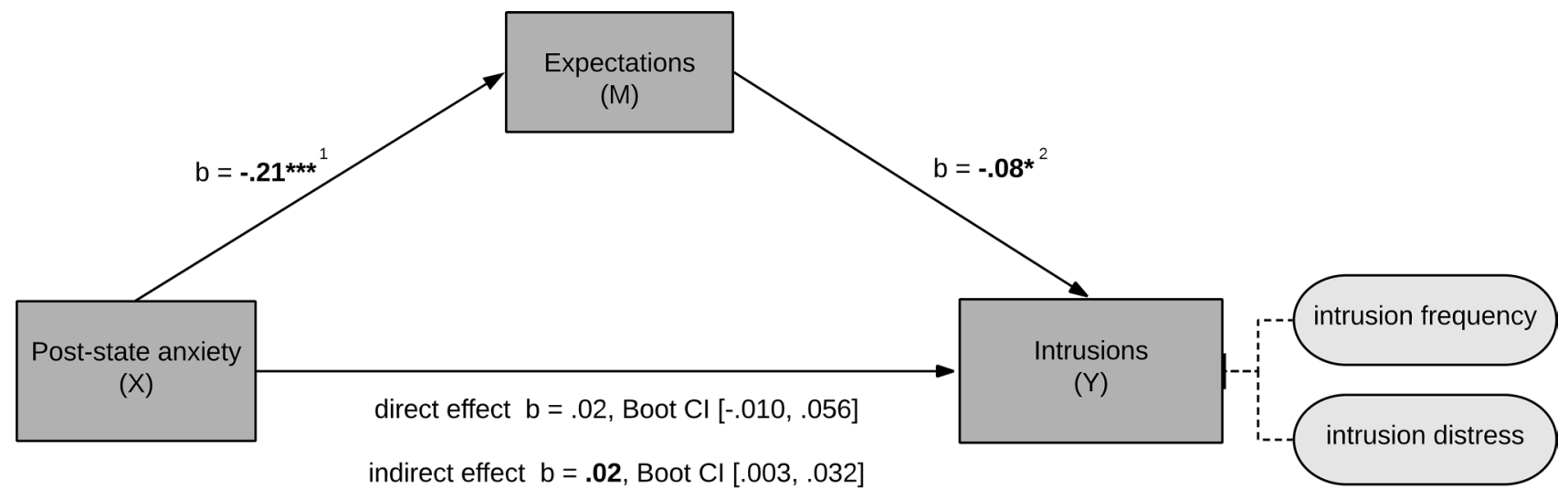

Significant results in bold.

Fig. 3 Results of the single mediation direct and indirect effect model. Note. Significance $* \mathrm{p}<.05, * * \mathrm{p}<.01, * * * \mathrm{p}<.001{ }^{1}$ Boot $\mathrm{CI}[-.281,-$ $.132],{ }^{2}$ Boot CI $\left.[-.141,-.013]\right)$.

considering only those diary entries that met the pre-specified criteria for intrusive memories, the significant group differences disappeared, $F(2,86)=1.44, p=.24, \eta_{p}^{2}=.03$. Thus, the three groups did not differ in the frequency of "valid" intrusions over 1 week. In line, the one-way ANOVA indicated no significant differences between the experimental groups in the severity of intrusive memories, $\mathrm{F}(2$, 72) $=0.90, \mathrm{p}=.41, \eta_{\mathrm{p}}^{2}=.02$.

\section{Results for the Secondary Outcomes}

\section{Distress Caused by the Trauma Film}

With regard to distress associated with the trauma film, no significant differences between the groups were found neither for the total score of the IES-R, $F(2,86)=0.50, p=.61$, $\eta_{p}^{2}=.01$, nor for the intrusion subscale, $F(2,86)=0.33$, $p=.72, \eta_{p}^{2}=.01$.

\section{Intrusion Provocation Task}

A one-way ANOVA did not reveal significant group differences in the intrusion provocation task, $F(2,86)=0.33$, $p=.72, \eta_{p}^{2}=.01$.

\section{Mediation Analysis}

The total effect of the independent variable "post-state anxiety" (X) on the dependent variable "intrusion experience" (Y) was analysed. The results showed that the post-state anxiety significantly influenced the intrusion experience and explained $7 \%$ of the variance in the dependent variable, $F(1$, $87)=6.24, p<.01, R^{2}=.07$. According to Cohen (1992), this corresponds to a small to medium effect $\left(f^{2}=.07\right)$. The regression analysis showed that the post-state anxiety significantly predicted the intrusion experience, $b=.04$, $t=2.50, p<.01, C I[.008, .070]$. The results of the indirect effect showed that the influence of the post-state anxiety (X) on the intrusive experience $(\mathrm{Y})$ was mediated by expectations (M), $b_{\text {indirect }}=.02$, boot $C I[.003, .032]$. Including the mediator, there was no significant direct effect of post-state anxiety on the intrusion experience, $b=.02, t=1.33, p=.17$, boot $C I[-.010, .056]$. This means that the influence of poststate anxiety on the intrusion experience was completely mediated via expectations. The results of this mediation analysis are visualized in Fig. 3.

For a more specific presentation, the results of the submodels are reported in Supplemental Material (see Supplemental Material 4).

Exploratory Analysis. In addition to the composite score of intrusions as measured by the intrusion diary and intrusions as assessed with the IES-R intrusion subscale, we also ran the mediation analysis separately for each intrusion score. The results of these separate analyses revealed a significant mediation of post-state anxiety on the IES-R intrusion subscale via expectations, but no significant mediation with the intrusion diary as the dependent variable. Thus, it seems that the association of expectations with intrusions is more apparent when the extent of distress related to the experience of intrusions is considered, as compared with the frequency of intrusions per se over 1 week. The results of these mediation analyses can be found in the Supplemental Material (see Supplemental Material 5).

\section{Discussion}

The aim of the present study was to investigate the role of expectations in the development of intrusive memories as a core feature of PTSD by using a well-established 
experimental paradigm - the trauma film paradigm-in a healthy student sample. After undergoing the standard TFP, expectations about the intensity and controllability of intrusions were manipulated using verbal suggestions via film-clip. We examined whether this manipulation of expectations influenced the experience of intrusions over the subsequent week; moreover, we examined whether expectations, across groups, mediated the effects of post-film state-anxiety on the experience of intrusions.

With regard to the operationalization of the TFP, the results speak to an adequate implementation of the procedure. Also, the results of the follow-up interview regarding the experience of the trauma film and the diary compliance rating are comparable to other TFP studies, thus supporting the representativeness of the findings (e.g., Arnaudova \& Hagenaars, 2017; Holmes et al., 2004; James et al., 2015; Laposa \& Alden, 2008; Laposa \& Rector, 2012; Măirean \& Ceobanu, 2017; Weidmann et al., 2009; Woud et al., 2013). Moreover, the average intrusion frequency and intrusion distress also corresponds well to the results of similar studies.

The main hypothesis of the present study was not confirmed; that is, the experimental groups did not differ in their experience of intrusive memories (at least when considering only the "valid" diary entries). Most likely, this was related to the unsuccessful manipulation, which failed to differentially manipulate participants' expectations as reflected in the non-significant manipulation check. Two interpretations may account for this failure: (1) it was not possible to manipulate participants' expectations through experimental procedures (i.e., verbal suggestions via film-clip as used in the present study) as participants may have their own idiosyncratic expectations about involuntary memories which might not be amenable to experimental manipulations; (2) it might be that our manipulation was merely not strong enough to alter participants' expectations. The second interpretation is supported by the descriptive results, suggesting that the negative expectations group indeed had the least positive expectations and the positive expectations group the most positive expectations; similarly, the descriptive results for the primary and secondary outcomes also (at least in part) support the hypothesized order of the groups with respect to their intrusion experience. However, delivering a manipulation aimed at producing larger differences in participants' expectations is not without risk: it may be problematic from an ethical point of view to induce even more pronounced expectations about the intensity and uncontrollability in the negative expectations group.

The results from the mediation analysis support our second hypothesis, indicating that the effects of post-film state-anxiety on the frequency and distress of intrusions was-in a statistical sense-fully mediated by expectations after watching the trauma-film. That is, a higher degree of post-state anxiety was associated with more negative expectations, which in turn predicted a stronger experience of intrusions. In other words, post-state anxiety seems to form expectations that in turn were linked to intrusive memories. This finding suggests that expectations may indeed be involved in the development of intrusions, but this may be driven by inter-individual variability in expectations rather than by the effects of the experimental manipulation. While a previous study showed that dysfunctional expectations are closely related to PTSD symptoms in a clinical sample (Herzog et al., 2021), the present study is, to our knowledge, the first to examine the potential influence of expectations on intrusive memories as a core feature of PTSD in an experimental approach. Although the present findings do not allow such a causal link given the non-significant group differences, the results of the mediation analysis do support the suggestion that people with more pronounced negative expectations about the intensity and uncontrollability of intrusions have a higher risk for the development of intrusive memories. The results from the mediation analysis also support the hypothesis of Laposa and Alden (2008), assuming that the influence of post-state anxiety on intrusive experience is mediated via cognitive processes. Moreover, our results are in line with current theories from neuroscience and computational psychiatry highlighting the influence of prior beliefs on symptom perception in PTSD (Kube et al., 2020; Linson \& Friston, 2019; Wilkinson et al., 2017).

Our results concerning post-film state-anxiety are also consistent with the previous theoretical assumption that higher post-state anxiety causes also a lower self-efficacy (Bandura, 1988, 2010). In our study, subjects with a high post-state anxiety thus estimated their self-efficacy in dealing with intrusions (e.g., "If I will re-experience contents of the film in the next week, I will be able to deal with it well.") significantly lower than subjects with a low poststate anxiety. At the same time, our results underline the finding that an increased sense of fear is associated with an increased expectation of the occurrence of future negative events (Dickson \& Moberly, 2013; MacLeod et al., 1997; Raune et al., 2005) and thus has an important influence on the perceived psychological stress (Dyrbye et al., 2006): In our study, subjects with a high post-state anxiety associated the expectation of the occurrence of intrusions with a higher level of physical and psychological impairment (e.g., "If I re-experience contents of the film in the next week, this will mean extreme stress for my body."). The statistically significant negative influence of expectations on intrusion experience in our study, in turn, is congruent with established cognitive models and theories that ascribe a central role to dysfunctional cognitions in the development and maintenance of PTSD (Botsford et al., 2019; Brewin et al., 1996; Ehlers \& Clark, 2000; Foa et al., 1989; Horowitz, 1986; Resick \& Schnicke, 1992). 


\section{Implications}

Replicating previous research, this study demonstrated that anxiety during or after the exposure to a potentially traumatic event is a relevant risk factor of the development of intrusive memories. Since this effect was mediated by expectations, it may provide some implications for the understanding of intrusions in PTSD, although we acknowledge that experimental research on the TFP using healthy samples allows only limited conclusions about PTSD. First, our results suggest that negative expectations about intrusions might emerge as a result of unpleasant emotional states following the analogue traumatic event (i.e., the trauma film). This formation of negative expectations might result from interoceptive inference (e.g., "I'm anxious, therefore I may not be able to control my thoughts and feelings"), i.e., drawing conclusions from an aversive emotional state (Gu et al., 2019). The emergence of such negative expectations may then precipitate the occurrence of intrusive memories, as our mediation analyses suggest. Thus, our results indicate that in people who experienced or witnessed an actual trauma, the level of anxiety experienced immediately after the traumatic event may shape expectations that are formed about the ability to cope with eventually occurring unpleasant thoughts or mental images. Such expectations, in turn, may critically determine the extent to which intrusive memories are formed subsequently. In other words, the dynamics between posttraumatic anxiety and future-directed expectations may be a risk factor for the development of intrusions and thus PTSD.

With all due caution given the experimental study design of this proof of principle study and when further replicated in healthy and more importantly traumatized samples, the current findings may also have some implications for the treatment and prevention of intrusions, specifically with regard to secondary prevention in terms of reducing the negative consequences of a traumatic event, e.g., in emergency ambulances. Conceivably, in view of the full mediation of the effects of post-film state-anxiety on intrusions through expectations, it might be useful to aim to promote positive expectations in people who experienced a traumatic event regarding their ability to cope with the aversive experiences from the traumatic situation. Although the non-significant group difference in the present study did not confirm that it is possible to enhance expectations about the controllability of intrusive memories through the provision of standardized information (i.e., video-clips), we do believe that this goal might be achieved in approaches other than psychoeducation which, however, would first have to be subject to future rigorous studies using healthy and traumatized samples. For instance, it might be possible to enhance people's expectations about the controllability of unpleasant thoughts by using a more idiosyncratic approach, e.g., by discussing with the persons how they managed to cope with their thoughts in previous situations and how this can be applied to their handling of the traumatic experience. Relatedly, positive expectations might also be promoted by discussing with the persons what specific strategies they could use should any intrusive memories come up. The potential of such expectation-optimizing psychological interventions has been shown both in people with physical symptoms (Kube et al., 2018b) and mental disorders (Rief \& Glombiewski, 2016). After being adapted and tested in experimental studies with different samples, such expectation-focused interventions to the processing of traumatic experiences could be a useful tool for (psychosocial) emergency care (i.e., "psychological first aid" or "psychosocial acute assistance") within $24 \mathrm{~h}$ after the exposure to a potentially traumatic event, with the aim of reducing possibly the risk for developing a full-blown PTSD.

\section{Strengths, Limitations and Future Research}

To date, there is no experimental study that has addressed the role of expectation effects as a potential influencing factor on the development of intrusions as a specific hallmark symptom of PTSD. As a specific strength, the study design should be particularly emphasized as it was a randomized controlled triple-blind study, i.e., that neither the participants nor the investigators and study coordinator were aware of the randomized assignment to the experimental conditions during the implementation or data analysis, therefore reducing distortions of the study results by Rosenthal and Hawthorne effects. Further strengths of the present study can be seen in the application of a conservative and highly standardized pre-screening approach for exclusion criteria due to ethical reasons, the use of a completely standardized study protocol, the validation of the newly developed expectations questionnaire, the adjustment for unspecific intrusive memories when evaluating the intrusion diary, the equal distribution of gender across experimental groups, and the use of a multimethod measure for mediation analyses. However, several limitations must be taken into account when interpreting the results:

A major limitation of our study is the non-significant manipulation check, i.e., our manipulation was probably too weak to manipulate individuals' expectations. Future studies should pay more attention to ensuring that both the manipulation videos are strong enough and the content of the manipulation videos is more sensitive to the selected dependent variable (frequency vs. distress). On the other hand, it is conceivable that strong emotional arousal in response to the trauma film may have subsequently restricted cognitive attention processes (Hariri et al., 2000; Hayes et al., 2012). Thus, it is possible that the manipulation of expectations linked to the trauma film could not be sufficiently internalized. In this regard, a promising approach is the cognitive assessment of the manipulation of expectations: According 
to Resick et al. (2016), the (partly chronic) hyperactivity of the amygdala in PTSD patients can be regulated by active training of the prefrontal cortex, which can restore the functional relationship between the two brain areas. This can be achieved through conscious (written or verbal) cognitive evaluation (Hariri et al., 2000, 2003). Within the framework of the TFP, participants could be given the task of writing down in a few sentences the content and takehome messages of the manipulation video they watched. The deliberate cognitive evaluation could consequently have a stronger influence on the participants' expectations in the hypothesized direction. Moreover, this intermediate step could be equivalent to an additional manipulation check. Alternatively, instead of presenting manipulated film clips, future studies could use an alternative approach such as the principle of "Cognitive Bias Modification (CBM)" (Woud et al., 2017): In recent years, more and more computer-based trainings have been developed that aim to modify cognitive processing (Tendolkar et al., 2019), which can be assumed to contribute to undesired emotional reactions or dysfunctional behavior (Hertel \& Mathews, 2011). A growing body of research has investigated this approach with respect to the development of PTSD within the TFP (e.g., Lang et al., 2009; Schartau et al., 2009; Vasterling \& Arditte Hall, 2018; Vermeulen et al., 2019; Woud et al., 2012, 2013, 2018). As the appraisal styles of the participants could be systematically distorted in a positive or negative direction by means of computer-assisted training leading to reduced or intensified PTSD-relevant symptoms (Woud et al., 2012), future studies could investigate whether such trainings could also be effective in systematically changing expectations. To this end, the CBM app used in previous studies (Vermeulen et al., 2019; Woud et al., 2012, 2013) would have to be adapted to expectations about the predicted distress caused by the intrusions and about coping self-efficacy capacities (as defined and measured in our study). All in all, such experience-based expectation manipulation might be more promising to change expectations toward intrusive memories after exposure to a trauma-like event. A further limitation of the present study is that we did not assess potential additional effects of the manipulation on constructs other than expectations, e.g., self-efficacy, reappraisal. Given that the manipulations comprised different elements, such an approach would have been valuable instead of focusing on the effects of expectations only. Moreover, future studies using TFP could adapt and validate the intrusion subscale of a more recent PTSD symptom questionnaire based on the DSM-5 (Weathers et al., 2013). The findings might also be explained in light of a lack of power of the study. Our a priori power analysis was based on the assumption of medium to large effects; hence, we might not have been able to detect smaller group differences. Indeed, the results for intrusion frequency were in the expected direction, but failed to reach significance. Thus, the lack of power is an additional limitation of the present study. Future studies may also consider assessing possible individual strategies applied in the control group to cope with the distressing film clips. Notably, another limitation is that the number of participants between the groups was different $(\mathrm{EG} 1=32, \mathrm{EG} 2=24$, $\mathrm{KG}=33$ ) because we accidently used randomization with replacement. As a result, this may have led to a variance limitation of the data and may have had an impact on our study results. Regarding the selectivity of the sample, nearly all participants in the study were students (98\%) indicating that the educational level of the sample was comparatively high: about $33 \%$ had a university degree. As a result, the age was comparatively low with an average of 24 years and persons of other age groups and educational status were clearly underrepresented. With regard to the development of PTSD or PTSD-related symptoms, a high level of education is a relevant protective factor (Bonanno et al., 2007; Murrell \& Norris, 1983) suggesting that the present sample might have been more resilient with regard to the development of intrusive memories. Yet, the majority of other TFP studies recruited quite similar samples, i.e., young students (James et al., 2016; Marks et al., 2018). With regard to the comparability of the study results, a representative sample can therefore be assumed. Nevertheless, future studies should try to include a larger variability concerning sociodemographic features in their samples (e.g., James et al. (2015) included participants ranging from 18 to 62 years).

Despite considering these study-specific limitations, future research should further pursue and optimize the expectation modification approach. This is particularly evident in view of the acute lack of evidence-based psychological interventions in emergency care, i.e., early psychological interventions after acute traumatization as secondary preventive strategies that are urgently needed (Holmes et al., 2018; James et al., 2016; National Institute for Clinical Excellence (NICE), 2005; Roberts et al., 2019; Rose et al., 2002; Sijbrandij et al., 2015).

\section{Conclusions}

Understanding the processes that contribute to the development and maintenance of intrusions is highly relevant in order to optimize the prevention and treatment of PTSD. The aim of the present study was to shed light on the role of expectation as one specific factor in development of intrusive memories using the trauma film paradigm. The results showed that watching the trauma film resulted in a significant increase in state anxiety, further supporting the empirical evidence that watching a trauma film elicits strong emotional reactions. Moreover, the results indicated that post-film state-anxiety influenced subsequent intrusive 
memories over 1 week, while this effect was completely mediated via expectations. Yet, the results showed no significant group differences, which can most likely be attributed to the failure of the manipulation to sufficiently change participants' expectations. Despite the non-significant group differences, the results from the mediation analysis suggest that dysfunctional expectations may play an important role in the development of intrusive memories. Future trauma film studies may aim to identify more powerful means to alter participants expectations after the exposure to an analogue stressor. To this end, the use of experience-based techniques such as the cognitive assessment of the manipulation of expectations (e.g., by a verbal or written summary of the content of the expectation manipulation) or computer-assisted trainings (e.g., CBM) might be promising to enhance memory consolidation of the expectation-changing information.

Supplementary Information The online version contains supplementary material available at https://doi.org/10.1007/s10608-022-10290-4.

Acknowledgment The authors are very grateful to the master students who likewise contributed to the study: Anna Hofmann, Matthias Feldmann.

Funding Open Access funding enabled and organized by Projekt DEAL. This research did not receive any specific grant from funding agencies in the public, commercial, or not-for-profit sectors.

\section{Declarations}

Conflict of interest Philipp Herzog, Charlotte Barth, Winfried Rief, Eva-Lotta Brakemeier, and Tobias Kube declare that they have no conflict of interest.

Research Involving Human Participants and/or Animals This study was performed in line with the principles of the Declaration of Helsinki. Approval was granted by the local ethics committee of the Department of Psychology at the Philipps-University Marburg (reference number 2019-07).

Informed Consent Informed consent was obtained from all individual participants included in the study.

Open Access This article is licensed under a Creative Commons Attribution 4.0 International License, which permits use, sharing, adaptation, distribution and reproduction in any medium or format, as long as you give appropriate credit to the original author(s) and the source, provide a link to the Creative Commons licence, and indicate if changes were made. The images or other third party material in this article are included in the article's Creative Commons licence, unless indicated otherwise in a credit line to the material. If material is not included in the article's Creative Commons licence and your intended use is not permitted by statutory regulation or exceeds the permitted use, you will need to obtain permission directly from the copyright holder. To view a copy of this licence, visit http://creativecommons.org/licenses/by/4.0/.

\section{References}

American Psychiatric Association. (2013). Diagnostic and statistical manual of mental disorders (5th ed.). https://doi.org/10.1176/ appi.books.9780890425596

Arnaudova, I., \& Hagenaars, M. A. (2017). Lights ... action: Comparison of trauma films for use in the trauma film paradigm. Behaviour Research and Therapy, 93, 67-77. https://doi.org/10. 1016/j.brat.2017.02.007

Bandura, A. (1988). Self-efficacy conception of anxiety. Anxiety Research, 1(2), 77-98. https://doi.org/10.1080/1061580880 8248222

Bandura, A. (2010). Self-efficacy. In The Corsini Encyclopedia of Psychology (pp. 1-3). Wiley. https://doi.org/10.1002/9780470479 216.corpsy0836

Benjet, C., Bromet, E., Karam, E. G., Kessler, R. C., McLaughlin, K. A., Ruscio, A. M., Shahly, V., Stein, D. J., Petukhova, M., Hill, E., Alonso, J., Atwoli, L., Bunting, B., Bruffaerts, R., Caldas-deAlmeida, J. M., de Girolamo, G., Florescu, S., Gureje, O., Huang, Y., et al. (2016). The epidemiology of traumatic event exposure worldwide: Results from the World Mental Health Survey Consortium. Psychological Medicine, 46(2), 327-343. https://doi. org/10.1017/S0033291715001981

Bonanno, G. A., Galea, S., Bucciarelli, A., \& Vlahov, D. (2007). What predicts psychological resilience after disaster? The role of demographics, resources, and life stress. Journal of Consulting and Clinical Psychology, 75(5), 671-682. https://doi.org/10. 1037/0022-006X.75.5.671

Bonanno, G. A., Westphal, M., \& Mancini, A. D. (2011). Resilience to loss and potential trauma. Annual Review of Clinical Psychology, 7(1), 511-535. https://doi.org/10.1146/annurev-clinp sy-032210-104526

Bootzin, R. R., \& Bailey, E. T. (2005). Understanding placebo, nocebo, and iatrogenic treatment effects. Journal of Clinical Psychology, 61(7), 871-880. https://doi.org/10.1002/jclp.20131

Botsford, J., Steinbrink, M., Rimane, E., Rosner, R., Steil, R., \& Renneberg, B. (2019). Maladaptive post-traumatic cognitions in interpersonally traumatized adolescents with post-traumatic stress disorder: An analysis of "Stuck-Points." Cognitive Therapy and Research, 43(1), 284-294. https://doi.org/10.1007/ s10608-018-9928-3

Brewin, C. R. (2015). Re-experiencing traumatic events in PTSD: New avenues in research on intrusive memories and flashbacks. European Journal of Psychotraumatology. https://doi.org/10.3402/ ejpt.v6.27180

Brewin, C. R., Andrews, B., \& Valentine, J. D. (2000). Meta-analysis of risk factors for posttraumatic stress disorder in trauma-exposed adults. Journal of Consulting and Clinical Psychology, 68(5), 748-766. https://doi.org/10.1037/0022-006X.68.5.748

Brewin, C. R., Dalgleish, T., \& Joseph, S. (1996). A dual representation theory of posttraumatic stress disorder. Psychological Review, 103(4), 670-686. https://doi.org/10.1037/0033-295X.103.4.670

Brewin, C. R., Gregory, J. D., Lipton, M., \& Burgess, N. (2010). Intrusive images in psychological disorders: Characteristics, neural mechanisms, and treatment implications. Psychological Review, 117(1), 210-232. https://doi.org/10.1037/a0018113

Brown, L. A., Belli, G. M., Asnaani, A., \& Foa, E. B. (2019). A review of the role of negative cognitions about oneself, others, and the world in the treatment of PTSD. Cognitive Therapy and Research, 43(1), 143-173. https://doi.org/10.1007/ s10608-018-9938-1

Bryant, R. A., Creamer, M., O’Donnell, M., Forbes, D., McFarlane, A. C., Silove, D., \& Hadzi-Pavlovic, D. (2017). Acute and chronic posttraumatic stress symptoms in the emergence of posttraumatic 
stress disorder a network analysis. JAMA Psychiatry, 74(2), 135142. https://doi.org/10.1001/jamapsychiatry.2016.3470

Cahill, L., \& McGaugh, J. L. (1998). Mechanisms of emotional arousal and lasting declarative memory. Trends in Neurosciences, 21(7), 294-299. https://doi.org/10.1016/S0166-2236(97)01214-9

Çili, S., \& Stopa, L. (2015). Intrusive mental imagery in psychological disorders: Is the self the key to understanding maintenance? Frontiers in Psychiatry. https://doi.org/10.3389/fpsyt.2015. 00103

Cohen, J. (1988). Statistical power analysis for the behavioral sciences. Lawrence Erlbaum Associates Publishers.

Cohen, J. (1992). A power primer. Psychological Bulletin, 112(1), 155-159. https://doi.org/10.1037/0033-2909.112.1.155

Colloca, L., \& Barsky, A. J. (2020). Placebo and nocebo effects. New England Journal of Medicine, 382(6), 554-561. https://doi.org/ 10.1056/nejmra1907805

Dickson, J. M., \& Moberly, N. J. (2013). Goal internalization and outcome expectancy in adolescent anxiety. Journal of Abnormal Child Psychology, 41(3), 389-397. https://doi.org/10.1007/ s10802-012-9685-9

Dyrbye, L. N., Thomas, M. R., \& Shanafelt, T. D. (2006). Systematic review of depression, anxiety, and other indicators of psychological distress among U.S. and Canadian medical students. In Academic medicine (Vol. 81, Issue 4, pp. 354-373). Lippincott Williams and Wilkins. https://doi.org/10.1097/00001888-20060 4000-00009

Ehlers, A., \& Clark, D. M. (2000). A cognitive model of posttraumatic stress disorder. Behaviour Research and Therapy, 38(4), 319-345. https://doi.org/10.1016/S0005-7967(99)00123-0

Ehlers, A., Hackmann, A., Steil, R., Clohessy, S., Wenninger, K., \& Winter, H. (2002). The nature of intrusive memories after trauma: The warning signal hypothesis. Behaviour Research and Therapy, 40(9), 995-1002. https://doi.org/10.1016/s00057967(01)00077-8

Ehlers, A., \& Steil, R. (1995). Maintenance of intrusive memories in posttraumatic stress disorder: A cognitive approach. Behavioural and Cognitive Psychotherapy, 23(3), 217-249. https://doi.org/10. 1017/S135246580001585X

Ehring, T., Kleim, B., \& Ehlers, A. (2011). Combining clinical studies and analogue experiments to investigate cognitive mechanisms in posttraumatic stress disorder. International Journal of Cognitive Therapy, 4(2), 165-177. https://doi.org/10.1521/ijct.2011.4.2.165

Eid, M., Gollwitzer, M., \& Schmitt, M. (2017). Statistik und Forschungsmethoden. Beltz.

Erdfelder, E., Faul, F., Buchner, A., \& Lang, A. G. (2009). Statistical power analyses using $\mathrm{G}^{*}$ Power 3.1: Tests for correlation and regression analyses. Behavior Research Methods, 41(4), 11491160. https://doi.org/10.3758/BRM.41.4.1149

Faul, F., Erdfelder, E., Lang, A. G., \& Buchner, A. (2007). G*Power 3: A flexible statistical power analysis program for the social, behavioral, and biomedical sciences. Behavior Research Methods, 39(2), 175-191. https://doi.org/10.3758/BF03193146

First, M. B., Spitzer, R. L., Gibbon, M., \& Williams, J. B. W. (1997). Structured clinical interview for DSM-IV axis I disorders SCIDI: Clinician version. American Psychiatric Publishing.

Foa, E. B., \& Kozak, M. J. (1986). Emotional processing of fear. Exposure to corrective information. In Psychological bulletin (Vol. 99, Issue 1, pp. 20-35). https://doi.org/10.1037/0033-2909.99.1.20

Foa, E. B., Steketee, G., \& Rothbaum, B. O. (1989). Behavioral/cognitive conceptualizations of post-traumatic stress disorder. Behavior Therapy, 20(2), 155-176. https://doi.org/10.1016/S00057894(89)80067-X

Foa, E. B., Zinbarg, R., \& Rothbaum, B. O. (1992). Uncontrollability and unpredictability in post-traumatic stress disorder: An animal model. Psychological Bulletin, 112(2), 218-238. https://doi.org/ 10.1037/0033-2909.112.2.218
Glombiewski, J. A., Rheker, J., Wittkowski, J., Rebstock, L., \& Rief, W. (2019). Placebo mechanisms in depression: An experimental investigation of the impact of expectations on sadness in female participants. Journal of Affective Disorders, 256, 658-667. https://doi.org/10.1016/j.jad.2019.06.070

Gu, X., FitzGerald, T. H. B., \& Friston, K. J. (2019). Modeling subjective belief states in computational psychiatry: Interoceptive inference as a candidate framework. Psychopharmacology (Berl), 236(8), 2405-2412. https://doi.org/10.1007/s00213-019-05300-5

Haag, C., Robinaugh, D. J., Ehlers, A., \& Kleim, B. (2017). Understanding the emergence of chronic posttraumatic stress disorder through acute stress symptom networks. JAMA Psychiatry, 74(6), 649-650. https://doi.org/10.1001/jamapsychiatry.2017.0788

Hagenaars, M. A., Brewin, C. R., van Minnen, A., Holmes, E. A., \& Hoogduin, K. A. L. (2010). Intrusive images and intrusive thoughts as different phenomena: Two experimental studies. Memory, 18(1), 76-84. https://doi.org/10.1080/0965821090 3476522

Hariri, A. R., Bookheimer, S. Y., \& Mazziotta, J. C. (2000). Modulating emotional responses: Effects of a neocortical network on the limbic system. NeuroReport, 11(1), 43-48. https://doi.org/10. 1097/00001756-200001170-00009

Hariri, A. R., Mattay, V. S., Tessitore, A., Fera, F., \& Weinberger, D. R. (2003). Neocortical modulation of the amygdala response to fearful stimuli. Biological Psychiatry, 53(6), 494-501. https:// doi.org/10.1016/S0006-3223(02)01786-9

Hayes, A. F. (2018). Introduction to mediation, moderation, and conditional process analysis, second edition: A regression-based approach. In The Guilford Press. www.guilford.com/MSS

Hayes, J. P., VanElzakker, M. B., \& Shin, L. M. (2012). Emotion and cognition interactions in PTSD: A review of neurocognitive and neuroimaging studies. Frontiers in Integrative Neuroscience, 6, 89. https://doi.org/10.3389/fnint.2012.00089

Hertel, P. T., \& Mathews, A. (2011). Cognitive bias modification: Past perspectives, current findings, and future applications. Perspectives on Psychological Science: A Journal of the Association for Psychological Science, 6(6), 521-536. https://doi. org/10.1177/1745691611421205

Herzog, P., Kaiser, T., Rief, W., Brakemeier, E., \& Kube, T. (2021). Assessing dysfunctional expectations in posttraumatic stress disorder-Development and validation of the Posttraumatic Expectations Scale (PTES). PsyArXiv. https://doi.org/10. 31234/osf.io/e6g4b

Holmes, E. A., \& Bourne, C. (2008). Inducing and modulating intrusive emotional memories: A review of the trauma film paradigm. Acta Psychologica, 127(3), 553-566. https://doi.org/10. 1016/j.actpsy.2007.11.002

Holmes, E. A., Brewin, C. R., \& Hennessy, R. G. (2004). Trauma films, information processing, and intrusive memory development. Journal of Experimental Psychology: General, 133(1), 3-22. https://doi.org/10.1037/0096-3445.133.1.3

Holmes, E. A., Ghaderi, A., Harmer, C. J., Ramchandani, P. G., Cuijpers, P., Morrison, A. P., Roiser, J. P., Bockting, C. L. H., O’Connor, R. C., Shafran, R., Moulds, M. L., \& Craske, M. G. (2018). The Lancet Psychiatry Commission on psychological treatments research in tomorrow's science. The Lancet Psychiatry, 5(3), 237-286. https://doi.org/10.1016/S2215-0366(17) 30513-8

Horn, J. L. (1965). A rationale and test for the number of factors in factor analysis. Psychometrika, 30(2), 179-185. https://doi.org/ 10.1007/BF02289447

Horowitz, M. J. (1986). Stress-response syndromes: A review of posttraumatic and adjustment disorders. Hospital and Community Psychiatry, 37(3), 241-249. https://doi.org/10.1176/ ps.37.3.241 
Iyadurai, L., Visser, R. M., Lau-Zhu, A., Porcheret, K., Horsch, A., Holmes, E. A., \& James, E. L. (2019). Intrusive memories of trauma: A target for research bridging cognitive science and its clinical application. Clinical Psychology Review, 69, 67-82. https://doi.org/10.1016/j.cpr.2018.08.005

James, E. L., Bonsall, M. B., Hoppitt, L., Tunbridge, E. M., Geddes, J. R., Milton, A. L., \& Holmes, E. A. (2015). Computer game play reduces intrusive memories of experimental trauma via reconsolidation-update mechanisms. Psychological Science, 26(8), 1201-1215. https://doi.org/10.1177/0956797615583071

James, E. L., Lau-Zhu, A., Clark, I. A., Visser, R. M., Hagenaars, M. A., \& Holmes, E. A. (2016). The trauma film paradigm as an experimental psychopathology model of psychological trauma: Intrusive memories and beyond. Clinical Psychology Review, 47, 106-142. https://doi.org/10.1016/j.cpr.2016.04.010

Kroenke, K., Spitzer, R. L., \& Williams, J. B. W. (2001). The PHQ-9. Journal of General Internal Medicine, 16(9), 606-613. https:// doi.org/10.1046/j.1525-1497.2001.016009606.x

Krüger-Gottschalk, A., Knaevelsrud, C., Rau, H., Dyer, A., Schäfer, I., Schellong, J., \& Ehring, T. (2017). The German version of the Posttraumatic Stress Disorder Checklist for DSM-5 (PCL-5): Psychometric properties and diagnostic utility. BMC Psychiatry, 17(1), 379. https://doi.org/10.1186/s12888-017-1541-6

Kube, T., Berg, M., Kleim, B., \& Herzog, P. (2020). Rethinking posttraumatic stress disorder: A predictive processing perspective. Neuroscience \& Biobehavioral Reviews, 113(April), 448-460. https://doi.org/10.1016/j.neubiorev.2020.04.014

Kube, T., Glombiewski, J. A., \& Rief, W. (2018b). Using different expectation mechanisms to optimize treatment of patients with medical conditions: A systematic review. Psychosomatic Medicine, 80(6), 535-543. https://doi.org/10.1097/PSY.0000000000 000596

Kube, T., Siebers, V. H. A., Herzog, P., Glombiewski, J. A., Doering, B. K., \& Rief, W. (2018a). Integrating situation-specific dysfunctional expectations and dispositional optimism into the cognitive model of depression: A path-analytic approach. Journal of Affective Disorders. https://doi.org/10.1016/j.jad.2017.12.082

Lang, T. J., Moulds, M. L., \& Holmes, E. A. (2009). Reducing depressive intrusions via a computerized cognitive bias modification of appraisals task: Developing a cognitive vaccine. Behaviour Research and Therapy, 47(2), 139-145. https://doi.org/10.1016/j. brat.2008.11.002

Laposa, J. M., \& Alden, L. E. (2008). The effect of pre-existing vulnerability factors on a laboratory analogue trauma experience. Journal of Behavior Therapy and Experimental Psychiatry, 39(4), 424-435. https://doi.org/10.1016/j.jbtep.2007.11.002

Laposa, J. M., \& Rector, N. A. (2012). The prediction of intrusions following an analogue traumatic event: Peritraumatic cognitive processes and anxiety-focused rumination versus rumination in response to intrusions. Journal of Behavior Therapy and Experimental Psychiatry, 43(3), 877-883. https://doi.org/10.1016/j. jbtep.2011.12.007

Lau-Zhu, A., Holmes, E. A., \& Porcheret, K. (2018). Intrusive memories of trauma in the laboratory: Methodological developments and future directions. Current Behavioral Neuroscience Reports, 5(1), 61-71. https://doi.org/10.1007/s40473-018-0141-1

Laux, L., Glanzmann, P., Schaffner, P., \& Spielberger, C. D. (1981). Das State-Trait-Angstinventar. Theoretische Grundlagen und Handanweisung. Beltz Test.

Linson, A., \& Friston, K. (2019). Reframing PTSD for computational psychiatry with the active inference framework. Cognitive Neuropsychiatry, 24(5), 347-368. https://doi.org/10.1080/13546805. 2019.1665994

MacLeod, A. K., Tata, P., Kentish, J., \& Jacobsen, H. (1997). Retrospective and prospective cognitions in anxiety and depression.
Cognition and Emotion, 11(4), 467-479. https://doi.org/10.1080/ 026999397379881

Maercker, A., \& Schützwohl, M. (1998). Erfassung von psychischen Belastungssfolgen: Die Impact of Event Skala-revidierte Version. Diagnostica, 44(3), 130-141. https://doi.org/10.1037/t01210-000

Măirean, C., \& Ceobanu, C. M. (2017). The relationship between suppression and subsequent intrusions: The mediating role of peritraumatic dissociation and anxiety. Anxiety, Stress, \& Coping, 30(3), 304-316. https://doi.org/10.1080/10615806.2016.1263839

Malik, A., Goodwin, G. M., Hoppitt, L., \& Holmes, E. A. (2014). Hypomanic experience in young adults confers vulnerability to intrusive imagery after experimental trauma: Relevance for bipolar disorder. Clinical Psychological Science, 2(6), 675-684. https://doi.org/10.1177/2167702614527433

Manea, L., Gilbody, S., \& McMillan, D. (2012). Optimal cut-off score for diagnosing depression with the Patient Health Questionnaire (PHQ-9): A meta-analysis. Canadian Medical Association Journal, 184(3), E191-E196. https://doi.org/10.1503/cmaj.110829

Marks, E. H., Franklin, A. R., \& Zoellner, L. A. (2018). Can't get it out of my mind: A systematic review of predictors of intrusive memories of distressing events. Psychological Bulletin, 144(6), 584-640. https://doi.org/10.1037/bul0000132

McLaughlin, K. A., Koenen, K. C., Hill, E. D., Petukhova, M., Sampson, N. A., Zaslavsky, A. M., \& Kessler, R. C. (2013). Trauma exposure and posttraumatic stress disorder in a national sample of adolescents. Journal of the American Academy of Child and Adolescent Psychiatry, 52(8), 815-830.e14. https://doi.org/10. 1016/j.jaac.2013.05.011

Michael, T., Ehlers, A., Halligan, S. L., \& Clark, D. M. (2005). Unwanted memories of assault: What intrusion characteristics are associated with PTSD? Behaviour Research and Therapy, 43, 613-628. https://doi.org/10.1016/j.brat.2004.04.006

Murrell, S. A., \& Norris, F. H. (1983). Resources, life events, and changes in psychological states: A prospective framework. American Journal of Community Psychology, 11(5), 473-491. https://doi.org/10.1007/BF00896800

National Institute for Clinical Excellence (NICE). (2005). Post-Traumatic Stress Disorder: The Management of PTSD in Adults and Children in Primary and Secondary Care: National Collaborating Centre for Mental Health (National Institute for Clinical Excellence (UK) \& National Collaborating Centre for Mental Health (UK) (ed.); Issue 26). Published by Gaskell and the British Psychological Society. https://doi.org/10.1192/pb. 30.9.357-a

Noé, G. (Director). (2002). Irréversible [Film]. StudioCanal.

Ozer, E. J., Best, S. R., Lipsey, T. L., \& Weiss, D. S. (2003). Predictors of posttraumatic stress disorder and symptoms in adults: A metaanalysis. Psychological Bulletin, 129(1), 52-73. https://doi.org/ 10.1037/0033-2909.129.1.52

Phelps, E. A. (2006). Emotion and cognition: Insights from studies of the human amygdala. Annual Review of Psychology, 57(1), 27-53. https://doi.org/10.1146/annurev.psych.56.091103.070234

Posner, K., Brown, G. K., Stanley, B., Brent, D. A., Yershova, K. V., Oquendo, M. A., Currier, G. W., Melvin, G. A., Greenhill, L., Shen, S., \& Mann, J. J. (2011). The Columbia-Suicide Severity Rating Scale: Initial validity and internal consistency findings from three multisite studies with adolescents and adults. American Journal of Psychiatry, 168(12), 1266-1277. https://doi.org/ 10.1176/appi.ajp.2011.10111704

Rattel, J. A., Grünberger, L. M., Reichenberger, J., Liedlgruber, M., Miedl, S. F., Blechert, J., \& Wilhelm, F. H. (2019). Frequency of intrusions and appraisal of related distress after analogue trauma: A comparative ecological momentary assessment methods study. Cognitive Therapy and Research, 43(1), 174-184. https://doi.org/ 10.1007/s10608-018-9941-6 
Raune, D., MacLeod, A., \& Holmes, E. A. (2005). The simulation heuristic and visual imagery in pessimism for future negative events in anxiety. Clinical Psychology and Psychotherapy, 12(4), 313-325. https://doi.org/10.1002/cpp.455

Rebstock, L., Schäfer, L. N., Kube, T., Ehmke, V., \& Rief, W. (2020). Placebo prevents rumination: An experimental study. Journal of Affective Disorders, 274, 1152-1160. https://doi.org/10.1016/j. jad.2020.06.010

Regambal, M. J., \& Alden, L. E. (2009). Pathways to intrusive memories in a trauma analogue paradigm: A structural equation model. Depression and Anxiety, 26(2), 155-166. https://doi.org/10.1002/ da. 20483

Resick, P. A., Monson, C. M., \& Chard, K. M. (2016). Cognitive processing therapy for PTSD: A comprehensive manual. Guilford Press.

Resick, P. A., \& Schnicke, M. K. (1992). Cognitive processing therapy for sexual assault victims. Journal of Consulting and Clinical Psychology, 60(5), 748-756. https://doi.org/10.1037//0022-006x. 60.5 .748

Rief, W., \& Glombiewski, J. A. (2016). Erwartungsfokussierte Psychotherapeutische Interventionen (EFPI). Verhaltenstherapie, 26(1), 47-54. https://doi.org/10.1159/000442374

Rief, W., Glombiewski, J. A., Gollwitzer, M., Schubö, A., Schwarting, R., \& Thorwart, A. (2015). Expectancies as core features of mental disorders. Current Opinion in Psychiatry, 28(5), 378-385. https://doi.org/10.1097/YCO.0000000000000184

Roberts, N. P., Kitchiner, N. J., Kenardy, J., Robertson, L., Lewis, C., \& Bisson, J. I. (2019). Multiple session early psychological interventions for the prevention of post-traumatic stress disorder. Cochrane Database of Systematic Reviews, 2019(8). https://doi. org/10.1002/14651858.CD006869.pub3

Rose, S. C., Bisson, J., Churchill, R., \& Wessely, S. (2002). Psychological debriefing for preventing post traumatic stress disorder (PTSD). Cochrane Database of Systematic Reviews. https://doi. org/10.1002/14651858.cd000560

Sareen, J. (2014). Posttraumatic stress disorder in adults: Impact, comorbidity, risk factors, and treatment. Canadian Journal of Psychiatry, 59(9), 460-467. https://doi.org/10.1177/0706743714 05900902

Schartau, P. E. S., Dalgleish, T., \& Dunn, B. D. (2009). Seeing the bigger picture: Training in perspective broadening reduces selfreported affect and psychophysiological response to distressing films and autobiographical memories. Journal of Abnormal Psychology, 118(1), 15-27. https://doi.org/10.1037/a0012906

Sijbrandij, M., Kleiboer, A., Bisson, J. I., Barbui, C., \& Cuijpers, P. (2015). Pharmacological prevention of post-traumatic stress disorder and acute stress disorder: A systematic review and metaanalysis. The Lancet Psychiatry, 2(5), 413-421. https://doi.org/ 10.1016/S2215-0366(14)00121-7

Spielberger, C. D., Gorsuch, R. L., \& Lushene, R. E. (1970). Manual for the state-trait anxiety inventory. https://ubir.buffalo.edu/ xmlui/handle/10477/2895

Tabachnick, B. G., \& Fidell, L. S. (2013). Using multivariate statistics. Pearson Education

Tendolkar, I., Vrijsen, J. N., \& Becker, E. S. (2019). Cognitive bias modification as possible add-on therapy for depression: State of research. Psychotherapeut, 64(3), 180-185. https://doi.org/10. 1007/s00278-019-0354-0
Trickey, D., Siddaway, A. P., Meiser-Stedman, R., Serpell, L., \& Field, A. P. (2012). A meta-analysis of risk factors for post-traumatic stress disorder in children and adolescents. Clinical Psychology Review, 32(2), 122-138. https://doi.org/10.1016/j.cpr.2011.12. 001

Vasterling, J. J., \& Arditte Hall, K. A. (2018). Neurocognitive and information processing biases in posttraumatic stress disorder. Current Psychiatry Reports, 20(11). https://doi.org/10.1007/ s11920-018-0964-1

Vermeulen, M., Brown, A. D., Raes, F., \& Krans, J. (2019). Decreasing event centrality in undergraduates using cognitive bias modification of appraisals. Cognitive Therapy and Research, 43(1), 214-225. https://doi.org/10.1007/s10608-018-9936-3

von Trier, L. (Director). (2009). Antichrist [Film]. Artificial Eye.

Weathers, F. W., Blake, D. D., Schnurr, P. P., Kaloupek, D. G., Marx, B. P., \& Keane, T. M. (2013). The life events checklist for DSM-5 (LEC-5). Instrument Available from the National Center for PTSD at Www. Ptsd. va. Gov.

Weidmann, A., Conradi, A., Gröger, K., Fehm, L., \& Fydrich, T. (2009). Using stressful films to analyze risk factors for PTSD in analogue experimental studies: Which film works best? Anxiety, Stress and Coping, 22(5), 549-569. https://doi.org/10.1080/ 10615800802541986

Wilkinson, S., Dodgson, G., \& Meares, K. (2017). Predictive processing and the varieties of psychological trauma. Frontiers in Psychology, 8(OCT), 1840. https://doi.org/10.3389/fpsyg.2017. 01840

Woud, M. L., Holmes, E. A., Postma, P., Dalgleish, T., \& Mackintosh, B. (2012). Ameliorating intrusive memories of distressing experiences using computerized reappraisal training. Emotion, 12(4), 778-784. https://doi.org/10.1037/a0024992

Woud, M. L., Postma, P., Holmes, E. A., \& MacKintosh, B. (2013). Reducing analogue trauma symptoms by computerized reappraisal training-Considering a cognitive prophylaxis? Journal of Behavior Therapy and Experimental Psychiatry, 44(3), 312-315. https://doi.org/10.1016/j.jbtep.2013.01.003

Woud, M. L., Verwoerd, J., \& Krans, J. (2017). Modification of cognitive biases related to posttraumatic stress: A systematic review and research agenda. Clinical Psychology Review, 54, 81-95. https://doi.org/10.1016/j.cpr.2017.04.003

Woud, M. L., Zlomuzica, A., Cwik, J. C., Margraf, J., Shkreli, L., Blackwell, S. E., Gladwin, T. E., \& Ehring, T. (2018). Effects of appraisal training on responses to a distressing autobiographical event. Journal of Anxiety Disorders, 56, 26-34. https://doi.org/ 10.1016/j.janxdis.2018.03.010

Yehuda, R., Hoge, C. W., McFarlane, A. C., Vermetten, E., Lanius, R. A., Nievergelt, C. M., Hobfoll, S. E., Koenen, K. C., Neylan, T. C., \& Hyman, S. E. (2015). Post-traumatic stress disorder. Nature Reviews Disease Primers, 1(1), 15057. https://doi.org/ 10.1038/nrdp.2015.57

Publisher's Note Springer Nature remains neutral with regard to jurisdictional claims in published maps and institutional affiliations. 